\title{
Misdiagnosed sternoclavicular tuberculosis presenting as a non-healing ulcer
}

\author{
Mantu Jain (10, ${ }^{1}$ Debasish Parija, ${ }^{1}$ Pankaj Kumar 다, ${ }^{2}$ Suprava Naik ${ }^{3}$
}

${ }^{1}$ Department of Orthopaedics, All India Institute of Medical Sciences Bhubaneswar, Bhubaneswar, Orissa, India ${ }^{2}$ Department of General Surgery, All India Institute of Medical Sciences - Bhubaneswar, Bhubaneswar, Odisha, India ${ }^{3}$ Department of Radiodiagnosis, All India Institute of Medical Sciences Bhubaneswar, Bhubaneswar, India

Correspondence to Dr Mantu Jain; montu_jn@yahoo.com

Accepted 17 August 2021

Check for updates

(C) BMJ Publishing Group Limited 2021. No commercial re-use. See rights and permissions. Published by BMJ.

To cite: Jain $M$, Parija $D_{\text {, }}$ Kumar $\mathrm{P}$, et al. BMJ Case Rep 2021;14:e244454. doi:10.1136/bcr-2021244454

\section{DESCRIPTION}

Even in endemic areas, the sternoclavicular joint (SCJ) is a rare site for tuberculosis (TB), with reported rates of only 1\%-2\%. ${ }^{12}$ This rarity, accompanied by non-specific symptoms, minimal clinical signs, and complexity in interpreting the X-rays, causes many cases to be missed. ${ }^{3}$ Misdiagnosis leads to the impediment of proper treatment, further complicating the situation. We describe a case of SCJ TB that was drained, suspecting a pyogenic abscess. Histopathological confirmation of TB and initiation of antitubercular drugs led to complete resolution of the non-healing ulcer.

A 54-year-old woman presented with a painless ulcer over the medial end of the right-side clavicle with extension to the SCJ of 1 month duration (figure 1A). She developed this ulcer after incision and drainage of a painless swelling over the upper part of the right chest and neck. The swelling, which she noticed about 3 months back, progressed gradually to involve the right sternoclavicular area, extending to the right supraclavicular and infraclavicular area. There was no history of trauma or associated pain. Constitutional symptoms like fever, loss of appetite and weight loss were also absent. She denied a history of TB and close contact. She received treatment in a peripheral hospital. The treating surgeon suspected a diagnosis of a tubercular abscess. However, the diagnosis was excluded in the absence of constitutional symptoms, palpable lymph nodes and negative laboratory reports. Both the Cartridge-based nucleic acid amplification test and acid-fast bacilli smear were negative from the aspirate. The treating physician did not perform a tubercular culture. Both the MRI and CT scan suggested spreading abscess with bony involvement. The abscess was drained, and necrotic tissues were removed. She was treated with a combination of amoxycillin and clavulanic acid, empirically.

The final culture of the discharge was positive for Klebsiella pneumoniae. She was treated with drugs based on susceptibility testing; however, the details are not available. Later, the treating physician added linezolid, considering an inadequate response, evident by persistent discharge. However, the ulcer failed to heal with about 2 weeks of treatment with linezolid. The patient decided to visit our outpatient department after about a month of initial drainage. On examination, the patient was afebrile, and her vitals were within normal limits. An irregular ulcer with a well-defined margin and undermined edge of size about $8 * 6 \mathrm{~cm}$ in the greatest dimension was observed over the right sternoclavicular area, extending to the supraclavicular and infraclavicular area on the same side. An initial look suggested a healing ulcer with healthy granulation at the floor; however, careful examination revealed an indurated base with purulent discharge from under the margins while palpation. In addition, an irregularity was also observed over the underlying bone.

Blood parameters were slightly deranged with a haemoglobin of $11.2 \mathrm{~g} / \mathrm{dL}(13-17 \mathrm{~g} / \mathrm{dL})$, total leucocyte count of $10.700 \mathrm{~mm}^{3}\left(4000-11000 / \mathrm{mm}^{3}\right)$, erythrocyte sedimentation rate (ESR) of $38 \mathrm{~mm} /$ hour $(0-20 \mathrm{~mm} /$ hour$)$, and C-reactive protein (CRP) level of $8 \mathrm{mg} / \mathrm{L}(<1 \mathrm{mg} / \mathrm{L}))$. CT and MRI of the patient were reviewed (figure $2 \mathrm{~A}-\mathrm{F}$ ). A peripherally enhancing collection with internal air foci in the lower neck and suprasternal notch was noted. The collection extends to the retrosternal space, right retroclavicular region, anterior to manubrium sterni, and superior part of the adjacent right anterior chest wall. We suspected a diagnosis of tubercular osteomyelitis of the right SCJ. A bone biopsy from the ulcer base was obtained. It showed giant cell granuloma with caseating necrosis, suggestive of a diagnosis of TB. She was treated with antitubercular therapy (ATT) for 12 months (2 months HRZE and 10 months HRE). At the end of 1 year, the wound is healed with some scarring (figure 1B).

SCJ TB is a rare presentation of osteoarticular $\mathrm{TB}^{4}$ It is unilateral in presentation and only rarely is a component of multicentric TB. ${ }^{56}$ There is some predisposition in females. ${ }^{3}$ The pathogenesis could be hematogenous or contiguous spread from adjoining lungs as proposed by Yasuda et al. ${ }^{7}$ Most of the time, there is delayed diagnosis or a misdiagnosis. ${ }^{2}$ The mean delay in diagnosis in a study by Meena et al was found to be 6 months. ${ }^{6}$ This can be attributed to the scarcity of symptoms, lack of clinical findings and difficulty interpreting plain radiographs. Occasionally, swelling is 'cold' (lacking inflammation), painless/pain referred to shoulder, and rarely a sinus/ulcer. Hence, a high index of suspicion is paramount for early diagnosis and treatment. Negative laboratory reports from the aspirate suggested a diagnosis other than TB. Only a bone biopsy could prove the diagnosis. Prakash et al advised an early MRI in patients with tenderness or swelling of 3 weeks duration in their series. $^{3}$ They also noted favourable outcomes with treatment when the ATT was started early $(<8$ weeks).

Late diagnosis can lead to ulceration/sinus formation. A more dreaded complication could be an erosion of vessels at the base of the neck or a mediastinal abscess. ${ }^{9}$ Unfamiliarity with the disease 

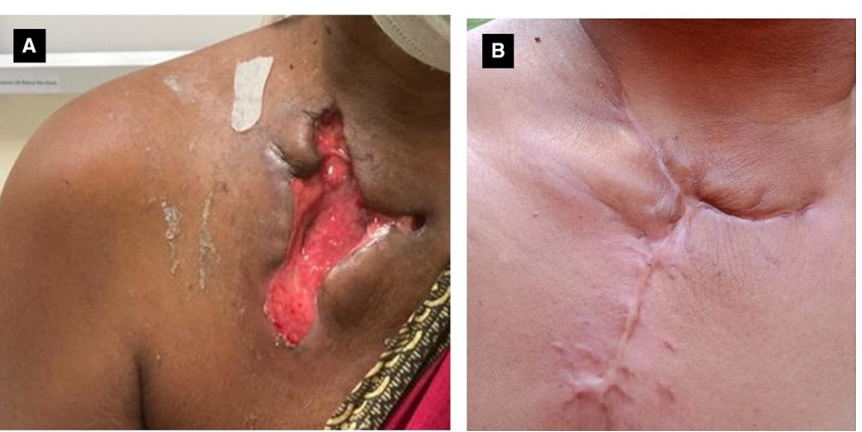

Figure 1 (A) Initial presentation with non-healing ulcer, and (B) post treatment with complete healing.

can lead to misdiagnoses and errors in treatment, which led to chronic ulceration, as in our case. Inadequate response to antibiotic therapy should lead to suspicion of underlying TB, particularly in endemic areas. ${ }^{4}$ Although the treating physician added a second-line antitubercular drug, linezolid, empirically, the medication was continued alone for 2 weeks. The patients should ideally be treated with first-line antitubercular drugs. The second-line drugs are reserved for resistant TB. Given poor elucidation of plain X-ray, authors have used a CT or an MRI to locate a pathology, especially in the early stages. ${ }^{310}$ Articular damage and abscess formation are better visualised on MRI. ${ }^{8}$ Definitive diagnosis can be made by isolating mycobacteria or confirmation with gene expert and histopathological findings. ${ }^{2}$

The common differential diagnosis of SC joint TB is Treitz syndrome, sternoclavicular hyperostosis, condensing osteitis,
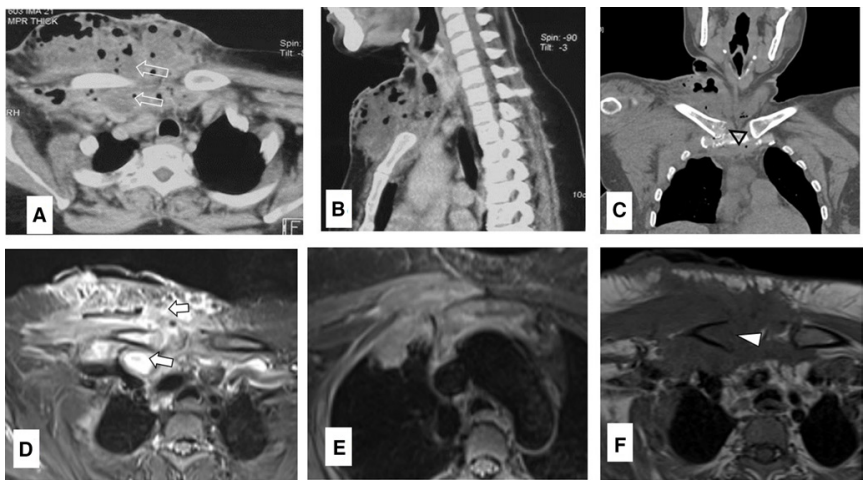

Figure 2 (A) Axial contrast enhanced CT scan, (B) sagittal reformatted image shows peripherally enhancing collection with internal air foci in the lower neck extending to retrosternal space, right retro clavicular region, anterior to manubrium sterni and adjacent right anterior chest wall (arrows). (C) Coronal reformatted image shows erosion of medial end of clavicle with involvement of right sternoclavicular joint. (D, E) Axial MRI turbo inversion recovery magnitude (TIRM) sequence shows the hyperintense collection and adjacent inflammation in corresponding areas, (E) axial T1WI shows signal alteration in adjacent clavicle (arrowhead). low-grade pyogenic infection, rheumatoid arthritis, myeloma and secondary deposits. ${ }^{1} 37$ Non-healing ulcers unresponsive to standard antibiotics could also include Buruli ulcer, which would mimic the histology findings but unlikely in the Indian subcontinent or cutaneous leishmaniasis (would fit with geographical location but not histology). ${ }^{11} 12$ Treatment is conservative in the form of ATT. However, surgical debridement may be required in patients not responding to conservative trials. ${ }^{3}$ In refractory cases, end-bloc resection can be carried out. ${ }^{4}$

\section{Learning points}

- Sternoclavicular tuberculosis is a rare presentation of osteoarticular tuberculosis requiring a high index of suspicion for diagnosis and treatment.

- Typical symptoms and signs of tuberculosis may be absent in sternoclavicular tuberculosis. Evaluation with MRI/CT is recommended for early diagnosis.

- Tissue biopsy from the involved bony segment can help to reach the diagnosis in a difficult situation.

Contributors $\mathrm{MJ}$ and PK were the treating doctors. DP was responsible for follow-up. SN gave the radiological images. MJ and DP wrote the manuscript where PK and SN gave critical inputs. All authors agree to the content of the manuscript.

Funding The authors have not declared a specific grant for this research from any funding agency in the public, commercial or not-for-profit sectors.

Competing interests None declared.

Patient consent for publication Obtained.

Provenance and peer review Not commissioned; externally peer reviewed.

\section{ORCID iDs}

Mantu Jain http://orcid.org/0000-0003-3848-4277

Pankaj Kumar http://orcid.org/0000-0003-2449-5514

\section{REFERENCES}

1 Jain A, Jajodia N, Aggarwal A, et al. Tuberculosis of the sternoclavicular joint. J Orthop Surg 2015;23:315-8.

2 Kurtz B, Hauss P-A, Druesne L, et al. Monoarthrite aiguë sternoclaviculaire tuberculeuse. Rev Med Interne 2005;26:251-3.

3 Prakash J, Sareen A, Arora P, et al. Sternoclavicular tuberculosis: an atypical imitator of refractory shoulder pain. Int Orthop 2020;44:693-8.

4 Sahu S. Sternoclavicular tuberculosis. Med J Armed Forces India 2008;64:373-4.

5 Saibaba B, Meena UK, Behera P, et al. Multicentric spinal tuberculosis with sternoclavicular joint involvement: a rare presentation. Case Rep Pulmonol 2014;2014:1-4

6 Meena UK, Saibaba B, Behera P, et al. Sternoclavicular joint tuberculosis: a series of 9 cases. Indian J Tuberc 2017:64:221-4.

7 Yasuda T, Tamura K, Fujiwara M. Tuberculous arthritis of the sternoclavicular joint. A report of three cases. J Bone Joint Surg Am 1995;77:136-9.

8 Shah J, Patkar D, Parikh B, et al. Tuberculosis of the sternum and clavicle: imaging findings in 15 patients. Skeletal Radiol 2000;29:447-53.

9 Pratima K, Vijay S, Shailendra K, et al. Tuberculosis of the sternoclavicular joint. J Orthop Trauma Rehab 2013;17:96-8.

10 Dhillon MS, Gupta RK, Bahadur R, et al. Tuberculosis of the sternoclavicular joints. Acta Orthop Scand 2001;72:514-7.

11 Yotsu RR, Murase C, Sugawara M, et al. Revisiting Buruli ulcer. J Dermatol 2015;42:1033-41.

12 Gurel MS, Tekin B, Uzun S. Cutaneous leishmaniasis: a great imitator. Clin Dermatol 2020;38:140-51 
Copyright 2021 BMJ Publishing Group. All rights reserved. For permission to reuse any of this content visit https://www.bmj.com/company/products-services/rights-and-licensing/permissions/

BMJ Case Report Fellows may re-use this article for personal use and teaching without any further permission.

Become a Fellow of BMJ Case Reports today and you can:

- Submit as many cases as you like

- Enjoy fast sympathetic peer review and rapid publication of accepted articles

Access all the published articles

Re-use any of the published material for personal use and teaching without further permission

Customer Service

If you have any further queries about your subscription, please contact our customer services team on +44 (0) 2071111105 or via email at support@bmj.com.

Visit casereports.bmj.com for more articles like this and to become a Fellow 